\title{
Review: antibiotics are moderately effective for acute otitis media
} in children

Glasziou PP, Del Mar CB, Sanders SL, et al. Antibiotics for acute otitis media in children. Cochrane Database Syst Rev 2004; (1):CD000219 (latest version 25 Aug 2003).

\section{$Q$ Are antibiotics effective in children with acute otitis media?}

\section{METHODS}

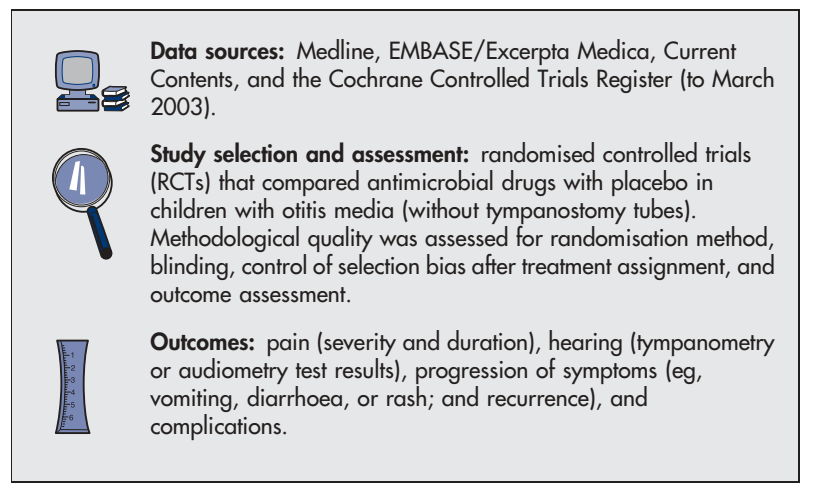

\section{MAIN RESULTS}

10 RCTs met the selection criteria, of which 8 included patient relevant outcomes. Study quality was generally high. Groups did not differ for resolution of pain at 24 hours, but fewer patients who received antibiotics still had pain at $2-7$ days (table). Of the trials that assessed hearing, no difference between groups was seen at 1 month ( 3 RCTs) or 3 months (2 RCTs). Vomiting, diarrhoea, or rash was increased in the antibiotics group (table). Groups did not differ for recurrence (table). Complications were rare in both groups (1 patient with mastoiditis).

\section{CONCLUSION}

In children with acute otitis media, antibiotics are effective for resolution of pain at 2-7 days, but the number needed to treat is 15 children in order to reduce pain in 1 child.

For correspondence: Professor P P Glasziou, University of Oxford, Oxford, UK. paul.glasziou@public-health.oxford.ac.uk

Source of funding: not stated.

\section{Commentary}

Tron he excellent review by Glasziou et al updates a previous review on this subject. The authors acknowledge 2 issues that immediately come to mind for the practitioner.

Firstly, the inclusion criteria for the studies varied, and this could have had a substantial effect on the meta-analysis. Acute otitis media has often been described as being overdiagnosed by practitioners, and the criteria for diagnosis are still debated. Appelman et al found that signs of tympanic inflammation did not predict the course of acute otitis media. ${ }^{1}$ Pneumatic otoscopy was proposed as an alternative criteria, but a review by Preston showed that pneumatic otoscopy predicted only serous otitis and not acute otitis media. ${ }^{2}$ Therefore, accurate diagnosis is still an issue and confounds conclusions about outcomes. Including children with minimal symptoms in trials might blunt the effect seen when treating those with genuine acute otitis media.

Secondly, when children present with red ear and pain, clinicians are presented with the dilemma of who to treat to reduce pain, while trying to avoid the occasional serious complications of hearing loss and mastoiditis, as well as overprescription of antibiotics. Little et al found that children with fever and vomiting were more likely to have poor outcomes and benefited from antibiotic treatment. ${ }^{3}$ Another study by Little et al proposed waiting 72 hours to treat. ${ }^{4}$ Either approach seems like a sensible solution based on the quality of current evidence.

Stephanie Wright, RN, PhD, CFNP, CPNP Georgetown University School of Nursing and Health Studies Washington, DC, USA

1 Appelman CL, Claessen JQ, Touw-Otten FW, et al. Severity of inflammation of tympanic membrane as predictor of clinical course of recurrent acute ofitis media. BMJ 1993;306:895

2 Preston K. Pneumatic otoscopy: a review of the literature. Issues Compr Pediatr Nurs 1998;21:117-28.

3 Little P, Gould C, Moore M, et al. Predictors of poor outcome and benefits from antibiotics in children with acute otitis media: pragmatic randomised trial. BMJ 2002;325:22.

4 Little P, Gould C, Williamson I, et al. Pragmatic randomised controlled trial of two prescribing strategies for childhood acute otitis media. BMJ $2001 ; 322: 336-42$.

Antibiotics $v$ placebo for acute otitis media in children*

\begin{tabular}{|c|c|c|c|c|c|}
\hline \multirow[b]{2}{*}{ Outcomes at $\leqslant 56$ days } & \multirow{2}{*}{$\begin{array}{l}\text { Number of } \\
\text { trials (patients) }\end{array}$} & \multicolumn{2}{|c|}{ Weighted event rates } & \multirow[b]{2}{*}{ RRI $(95 \%$ CI) } & \multirow[b]{2}{*}{ NNH } \\
\hline & & Antibiotics & Placebo & & \\
\hline \multirow[t]{2}{*}{ Pain at $\leqslant 24$ hours } & $3(717)$ & $38 \%$ & $37 \%$ & $2 \%(-15$ to 22$)$ & Not significant \\
\hline & & & & $\operatorname{RRR}(C l)$ & NNT (Cl) \\
\hline \multirow[t]{2}{*}{$\begin{array}{l}\text { Pain at 2-7 days } \\
\text { Recurrence }\end{array}$} & $\begin{array}{l}8(2287) \\
5(1669)\end{array}$ & $\begin{array}{l}15 \% \\
22 \%\end{array}$ & $\begin{array}{l}22 \% \\
22 \%\end{array}$ & $\begin{array}{l}30 \%(19 \text { to } 40) \\
0 \%(-19 \text { to } 17)\end{array}$ & $\begin{array}{l}15 \text { (10 to } 25) \\
\text { Not significant }\end{array}$ \\
\hline & & & & RRI (CI) & NNH (Cl) \\
\hline Vomiting, diarrhoea, or rash & $4(938)$ & $17 \%$ & $11 \%$ & 60 (19 to 116$)$ & $17(10$ to 50$)$ \\
\hline
\end{tabular}

*Abbreviations defined in glossary; weighted event rates, RRI, RRR, NNH, NNT, and Cl calculated from data in article using a fixed effects model. 